\title{
Moored Observations of Nonlinear Internal Waves near DongSha
}

\author{
Matthew H. Alford \\ Applied Physics Laboratory \\ 1013 NE $40^{\text {th }}$ Street \\ Seattle, WA 98105 \\ phone: (206) 221-3257 fax: (206) 543-6785 email: malford@apl.washington.edu \\ Grant Number: N00014-05-1-0283 \\ http://faculty.washington.edu/malford/
}

\section{LONG-TERM GOALS}

I am interested in the general problems of internal waves and the ocean mixing. Knowledge of these is important for advancing the performance of operational and climate models, as well as for understanding local problems such as pollutant dispersal and biological productivity. In the specific case of this DRI's focus, i.e., nonlinear internal waves (NLIW), the waves' currents and displacements are strong enough to impact Navy operations such as diving, ROV operation and mine detection/removal.

\section{OBJECTIVES}

- To understand the generation mechanisms and to predict the arrival times of large NLIWs in the northeastern South China Sea (SCS).

- To observe NLIW packets and estimate their energy and energy flux in the 2007 South China Sea experiment.

- To relate these to the energy and energy-flux in the low-mode tide, and to measurements of overturn-inferred turbulence.

\section{APPROACH}

Nonlinear internal waves are transient baroclinic phenomena where velocity and isopycnal displacements can be as large as $2 \mathrm{~m} / \mathrm{s}$ and $150 \mathrm{~m}$, respectively. The South China Sea, where they are particularly strong, was selected as one of the field-study regions for the NLIWI DRI in part because of the excellent historical context provided by the ASIAEX experiment (Ramp et al, 2004).

In planning the field experiment in the South China Sea component of NLIWI, Dongsha Island (in the western South China Sea, Figure 1) was identified as a location where the propagation, transformation and dissipation of the NLIW could be tractably studied, and where a coordinated multi-PI experiment near DongSha Island in the western South China Sea could be staged to study it. Central to our study is the following hypothesis: The low-mode internal tide propagates westward from Luzon strait in a narrow quasi-linear beam (Figure 1, arrows) aimed directly at Dongsha. When it reaches the steep continental slope, it steepens, nonlinearizes, and generates trains of nonlinear internal waves (NLIWs) that then propagate onto the shelf. Considerable evidence, presented previously, supports this 


\section{Report Documentation Page}

Form Approved

OMB No. 0704-0188

Public reporting burden for the collection of information is estimated to average 1 hour per response, including the time for reviewing instructions, searching existing data sources, gathering and maintaining the data needed, and completing and reviewing the collection of information. Send comments regarding this burden estimate or any other aspect of this collection of information,

including suggestions for reducing this burden, to Washington Headquarters Services, Directorate for Information Operations and Reports, 1215 Jefferson Davis Highway, Suite 1204, Arlington

VA 22202-4302. Respondents should be aware that notwithstanding any other provision of law, no person shall be subject to a penalty for failing to comply with a collection of information if it

does not display a currently valid OMB control number.

1. REPORT DATE

30 SEP 2007

4. TITLE AND SUBTITLE

Moored Observations Of Nonlinear Internal Waves Near DongSha

6. $\operatorname{AUTHOR}(\mathrm{S})$

7. PERFORMING ORGANIZATION NAME(S) AND ADDRESS(ES)

Applied Physics Laboratory,1013 NE 40th Street,Seattle,WA,98105

9. SPONSORING/MONITORING AGENCY NAME(S) AND ADDRESS(ES)

2. REPORT TYPE

Annual

00-00-2007 to 00-00-2007

5a. CONTRACT NUMBER

5b. GRANT NUMBER

5c. PROGRAM ELEMENT NUMBER

5d. PROJECT NUMBER

5e. TASK NUMBER

5f. WORK UNIT NUMBER

8. PERFORMING ORGANIZATION

REPORT NUMBER

10. SPONSOR/MONITOR'S ACRONYM(S)

11. SPONSOR/MONITOR'S REPORT NUMBER(S)

12. DISTRIBUTION/AVAILABILITY STATEMENT

Approved for public release; distribution unlimited

13. SUPPLEMENTARY NOTES

code 1 only

14. ABSTRACT

15. SUBJECT TERMS

16. SECURITY CLASSIFICATION OF:

a. REPORT

unclassified b. ABSTRACT unclassified c. THIS PAGE unclassified
17. LIMITATION OF ABSTRACT

Same as

Report (SAR)
18. NUMBER

OF PAGES

13 19a. NAME OF

RESPONSIBLE PERSON 
hypothesis; notably the occurrence of the strongest SAR signatures of NLIWs (orange lines) in the vicinity of this beam, near our study site at DongSha Island.

\section{WORK COMPLETED}

My component of the experiment was to design, deploy, and recover the MP1 and MP2 moorings (Figure 1, magenta squares) each of which featured one or two ADCPs to measure the NLIWs and a Moored Profiler (MP; Figure 2) crawling up and down a taut conventional mooring wire to measure the velocity and vertical displacements of the internal tides. As configured for this deployment, the MP's delivered full-water-column profiles of T, S, u and v each 90 and 20 minutes, respectively. These enable calculation of the following, none of which is possible with conventional moorings:

1. 10-m velocity, shear, strain and Richardson number. Each of these quantities has been shown to be related to the onset of turbulence (Gregg 1989, Alford and Pinkel 2001).

2. Energy flux in all vertical modes. Flux is computed as the covariance between baroclinic velocity and pressure anomaly, $<$ u'p' $>$ (Kunze et al, 2002). Conventional moorings can estimate energy flux in the lowest two modes (Alford, 2003); however, modal transformations here are strong, requiring denser vertical measurements.

3. Dissipation rate. Using the method of overturns (Thorpe 1977, Dillon 1982), reliable estimates of dissipation rate can be obtained by sorting the MP density profiles (Figure 3, bottom). The noise level is variable but is easily monitored using in-situ stratification (Alford et al 2006).

\section{RESULTS}

Preliminary analysis of the data indicates the following:

1. MP1 functioned well (Figure 3) for about 45 days. The MP stopped profiling for about three days near yearday 123, but the downlooking $75-\mathrm{KHz}$ ADCP record was nearly flawless. At spring tides, strong tidal and NLIW currents caused drawdowns of tens of meters (top, blue line), requiring correction of measured vertical velocities. Stronger drawdowns were avoided in this high-current region through use of high tension (about $1000 \mathrm{~kg}$ ) on the mooring wire.

2. Internal tidal currents (middle, colors) and displacements (black lines) were primarily diurnal and about $0.5-0.7 \mathrm{~m} / \mathrm{s}$ at spring tides. These showed a strong spring/neap cycle.

3. Dissipation rate, $\varepsilon$, was highly elevated two orders of magnitude in the lower $500 \mathrm{~m}$ during spring tides over that seen during neaps. Overturns during spring tide are $\mathrm{O}(100 \mathrm{~m})$ high, and appear to occur during high strain events (Figure 4) as has been observed previously (Alford and Pinkel 2001, Alford et al 2006), but the sense is different, with the high strain resulting from depressed isopycnals below the overturning region rather than elevated isopycnals above it. Preliminary model runs appear to reproduce this behavior (J. Klymak, pers. comm.). The magnitude of the depth-integrated dissipation (Figure 5), assuming it occurs in a 25-km band spanning the slope, is sufficient to remove about $20 \%$ of the incoming energy flux from the linear internal tide (right axis label). 
4. The NLIWs are not well resolved in the 1.5-hour-sampling of the MP measurements at MP1. However, they are easily resolved with the $75 \mathrm{KHz}$ ADCP looking downward from about $70 \mathrm{~m}$ (Figure 2, right) that pinged much more frequently (1-minute ensembles). Their passage and spring/neap cycle are evident in the vertical velocity at $200 \mathrm{~m}$ (Figure 3 top, green). The structure of a typical wave during the intensive observation period is shown in Figure 6 . It is clear that while care is required in correcting for mooring motion and migrating scatterers, the vertical and horizontal velocity of the waves is well resolved.

5. The timing of the wave arrivals appears consistent with the results of Zhao and Alford (2006) and several other datasets presented at the Girdwood meeting; namely, waves occur $\Delta \mathrm{t}$ after each westward current maximum, where $\Delta \mathrm{t}$ is the travel time of an irrotational mode- 1 wave (Figure 7). Only periods where two peaks occur in one day appear to generate waves, as argued by Zhao and Alford (2006) and Chris Jackson.

6. Energy flux (returning to Figure 5) shows a clear spring neap cycle in both the diurnal (middle, blue) and semidiurnal bands (green). The mean diurnal flux of $7.5 \mathrm{kWm}^{-1}$ is substantially greater than its semidiurnal counterpart of $3.0 \mathrm{kWm}^{-1}$. At MP2 (not shown), the flux in both bands is $<0.5 \mathrm{kWm}^{-1}$, indicating that nearly all energy has been transferred out of the linear internal tide by this point.

7. Velocity and displacements at MP2 (Figure 8) show a complicated structure consisting of a mixture of tidal and NLIW motions. Many waves are present. They are much better resolved in the MP measurements here than at MP1, owing to the 20-minute cycle time. 


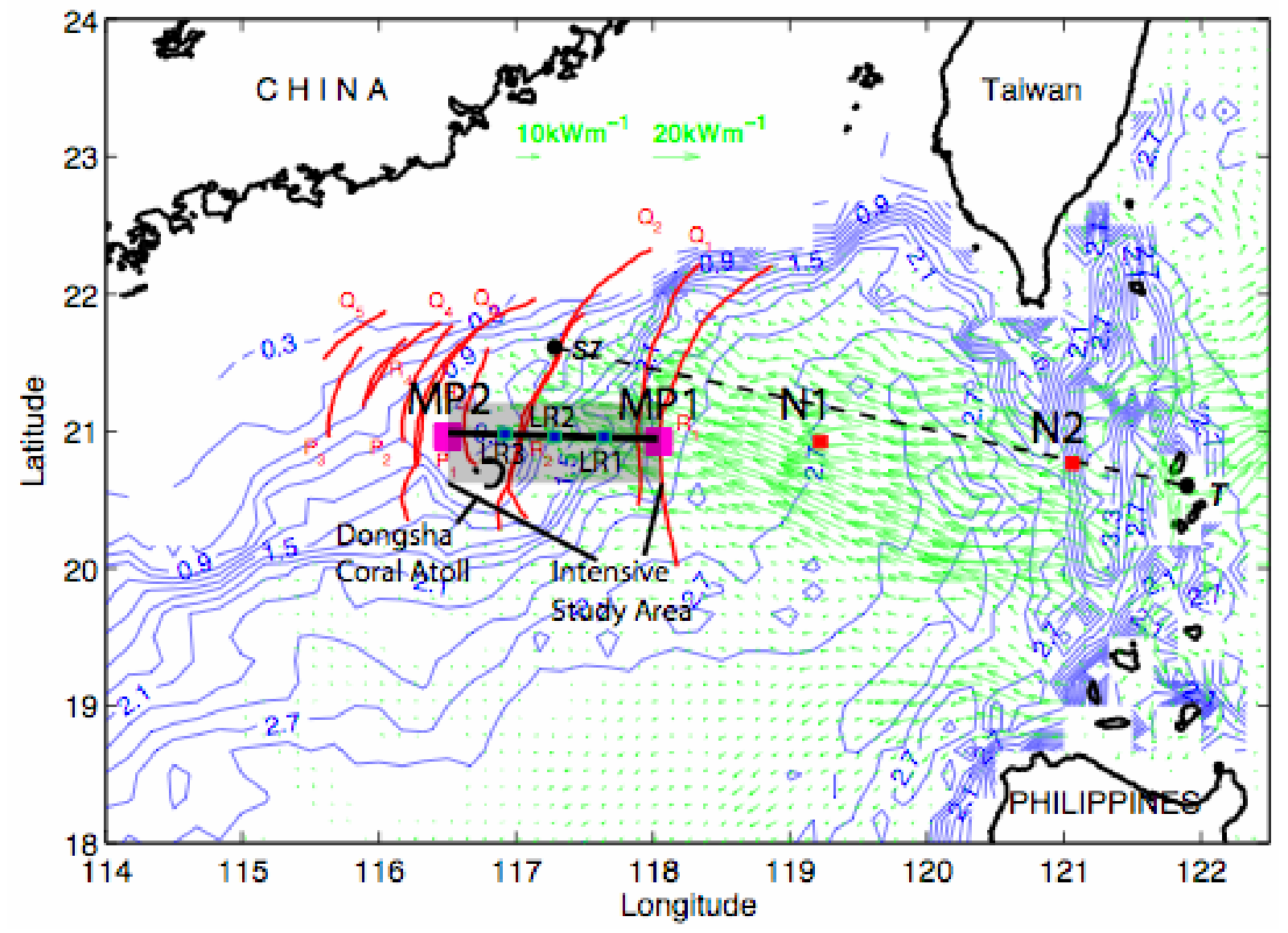

Figure 1: Depth-integrated M2 energy fluxes from a numerical simulation (Niwa and Hibiya 2004). The DongSha experiment (gray box) is sited in a beam of intensified energy flux from Luzon Strait (arrows), and in the region where the most SAR signatures have been detected (orange; Zhao et al, 2004). The moorings deployed during the experiment are indicated with dots. 


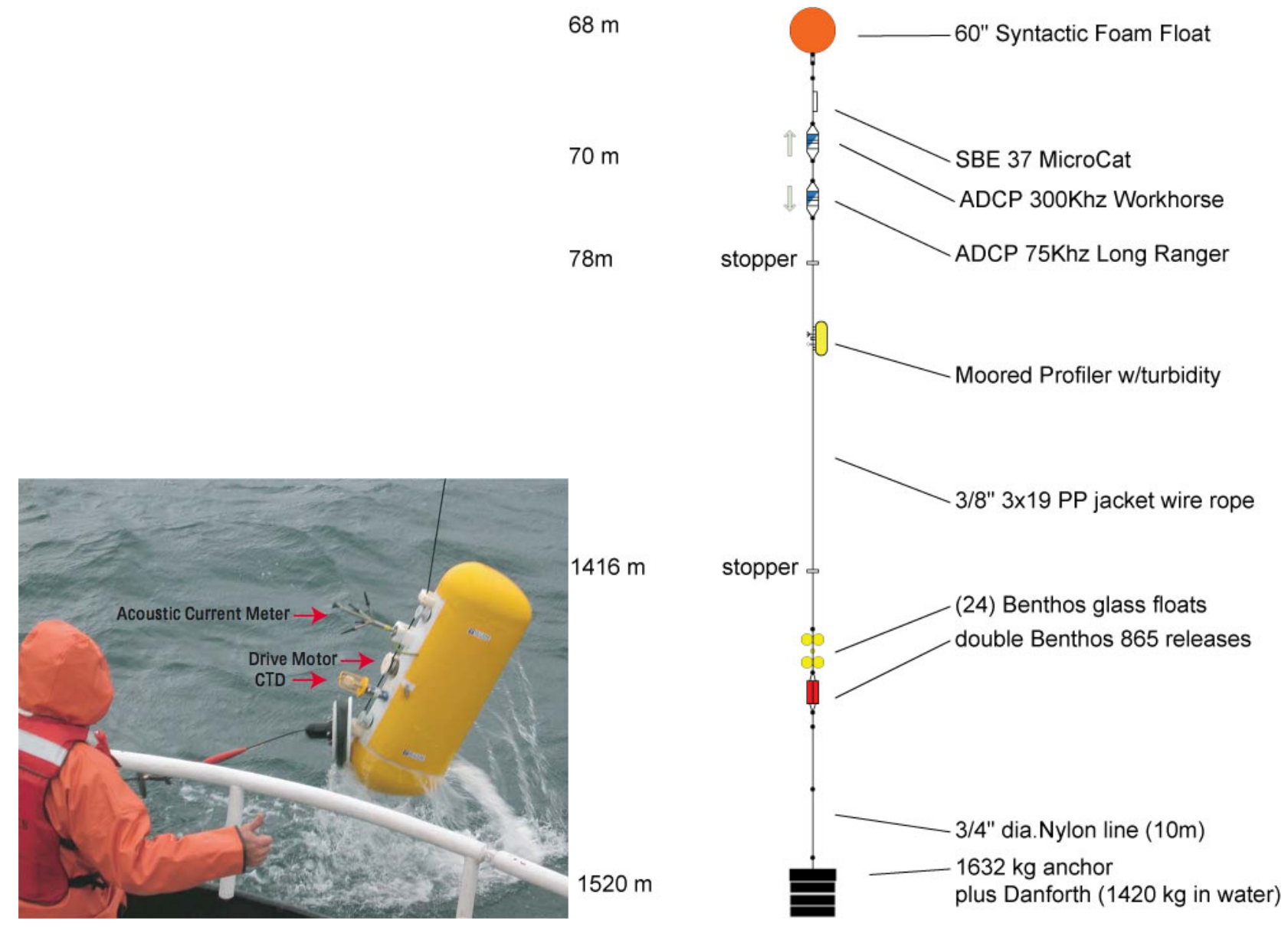

Figure 2: (Left) The McLane Moored Profiler being recovered in Puget Sound, WA. (Right) Mooring diagram at MP1. The uplooking ADCP did not function owing to a failed memory card. The shallow mooring at MP2 (not shown) is similar, with the MP sampling the range 60-300 $m$ in $320 m$ of water. 


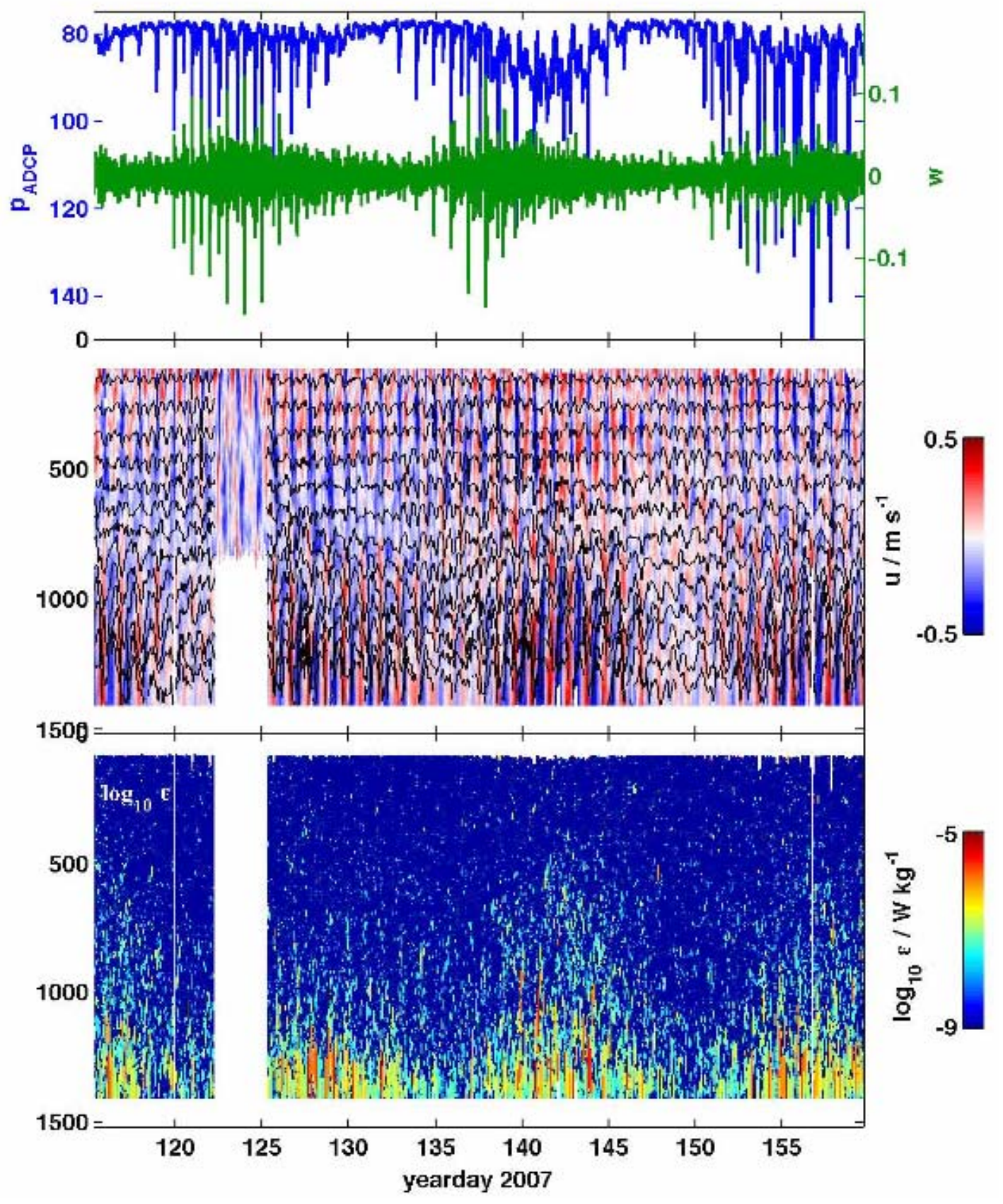

Figure 3: Summary of the 45-day mooring deployment at MP1. (top) Pressure measured at the top of the mooring (blue; axis at left) and vertical velocity measured at 200 m (green; axis at right). (middle) East-west velocity (colors) and isopycnal displacements (black). Velocities in the upper 800 $m$ are from the $75 \mathrm{KHz} A D C P$; below that they are from the MP. (bottom) Turbulent dissipation rate, E, measured from Thorpe scale analysis of density profiles from the MP. Current speed, dissipation, displacement, and the occurrence of waves all show clear spring/neap cycles after westward current maxima (dashed lines). 


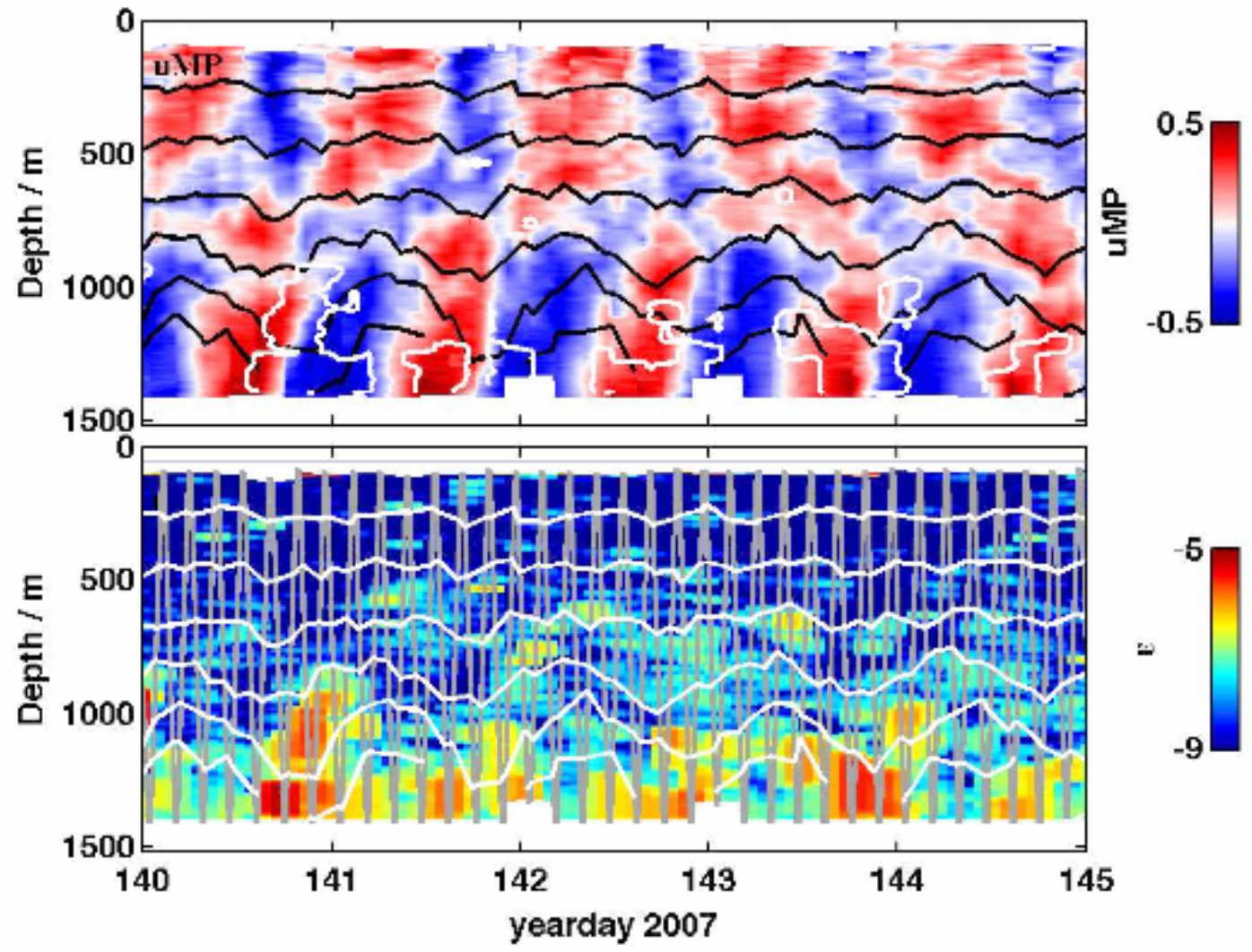

Figure 4: Velocity (top) and dissipation rate, (bottom) measured with the MP over a 5day period during a spring tide. Isopycnals are overlaid. Regions of $\varepsilon>10^{-6.5} \mathrm{Wkg}^{-1}$ are outlined in white. Strong dissipations occur owing to strain events associated with diurnal internal tide motions on the sloping bottom. The moored profiler track (bottom, gray) indicates that these motions are well resolved. 


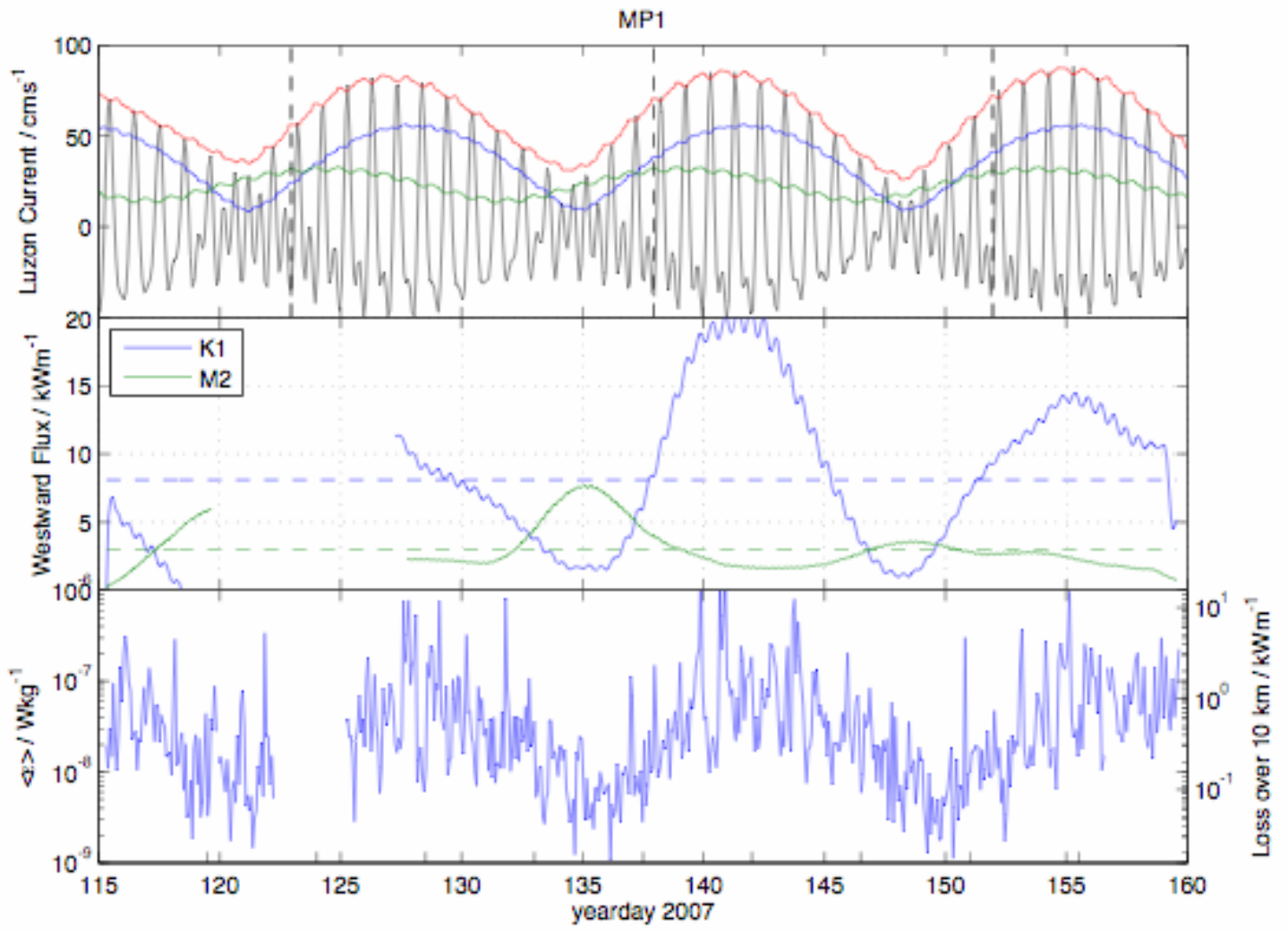

Figure 5: Energy flux and integrated dissipation at MP1. (top) East-west barotropic tidal currents at Luzon Strait from OTIC (black), together with its semidiurnal (green) and diurnal (blue) components, and their sum (red). To compare with quantities at MP1, the tidal current time series are lagged by 47 hours, the travel time of an irrotational mode-1 linear internal wave as in Zhao and Alford (2006). (middle) Flux, estimated from harmonic fits in 3-day temporal windows, in the semidiurnal (green) and diurnal (blue) bands. Note the gap near yearday 123 is widened owing to these windows. (bottom) Depth-averaged dissipation rate (left axis) and its volume integral over depth and a 25-km-wide strip. 


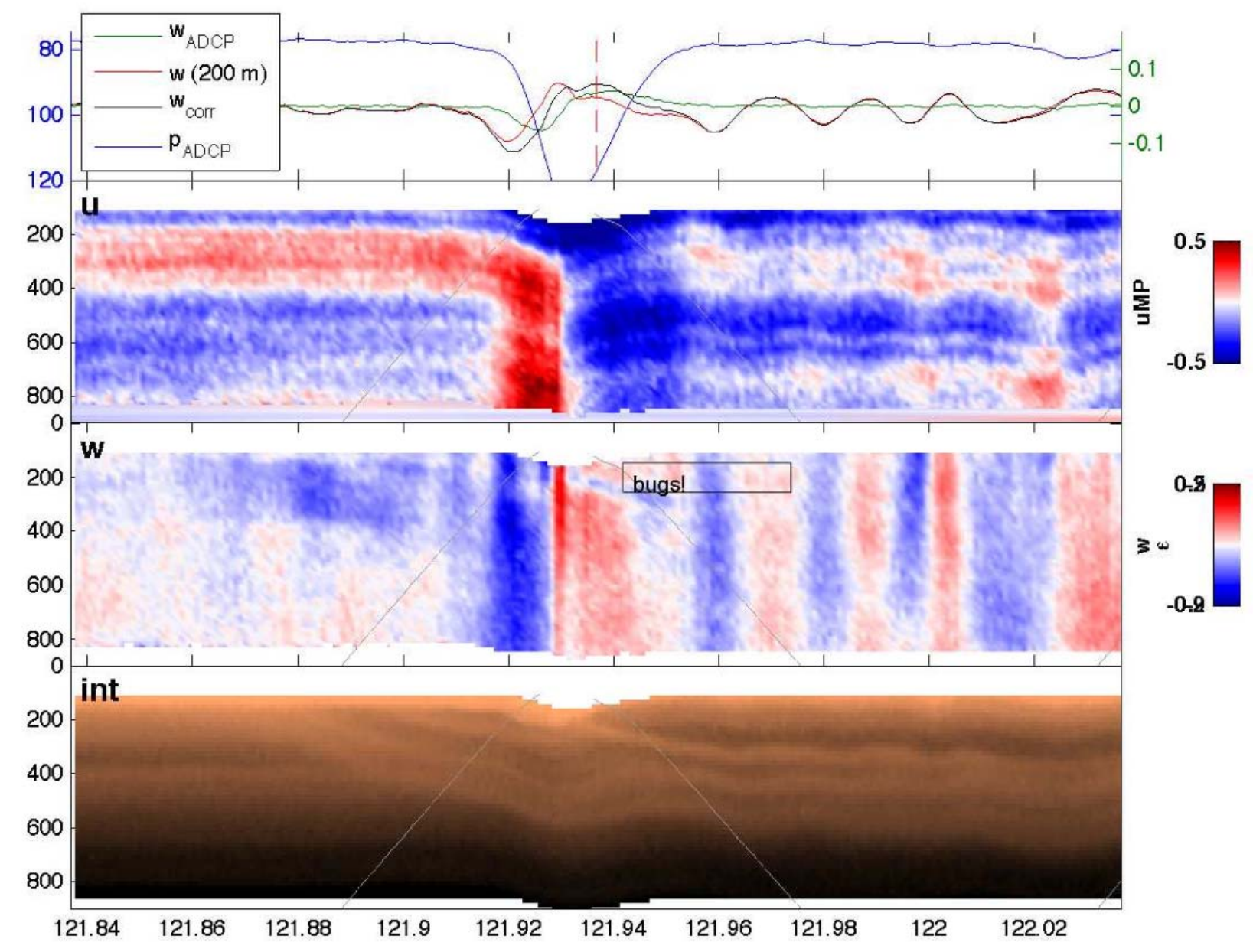

Figure 6: A sample wave event detected at MP1. A 2.5-hour period is plotted of only the upper $800 \mathrm{~m}$. (top) Depth of the ADCP (blue; scale at left), showing drawdown of the mooring as the wave passed, and the vertical velocity measured by the ADCP at $200 \mathrm{~m}$ (red; scale at right). It is straightforward to correct measured signals using the measured mooring motion to produce a corrected vertical velocity (green). The associated $u, w$ and intensity signals are shown below. Note the spurious vertical velocity signals associated with vertically migrating scatterers. The gray lines in the lower panels show the path of the moored profiler, indicating its coarse temporal resolution. 

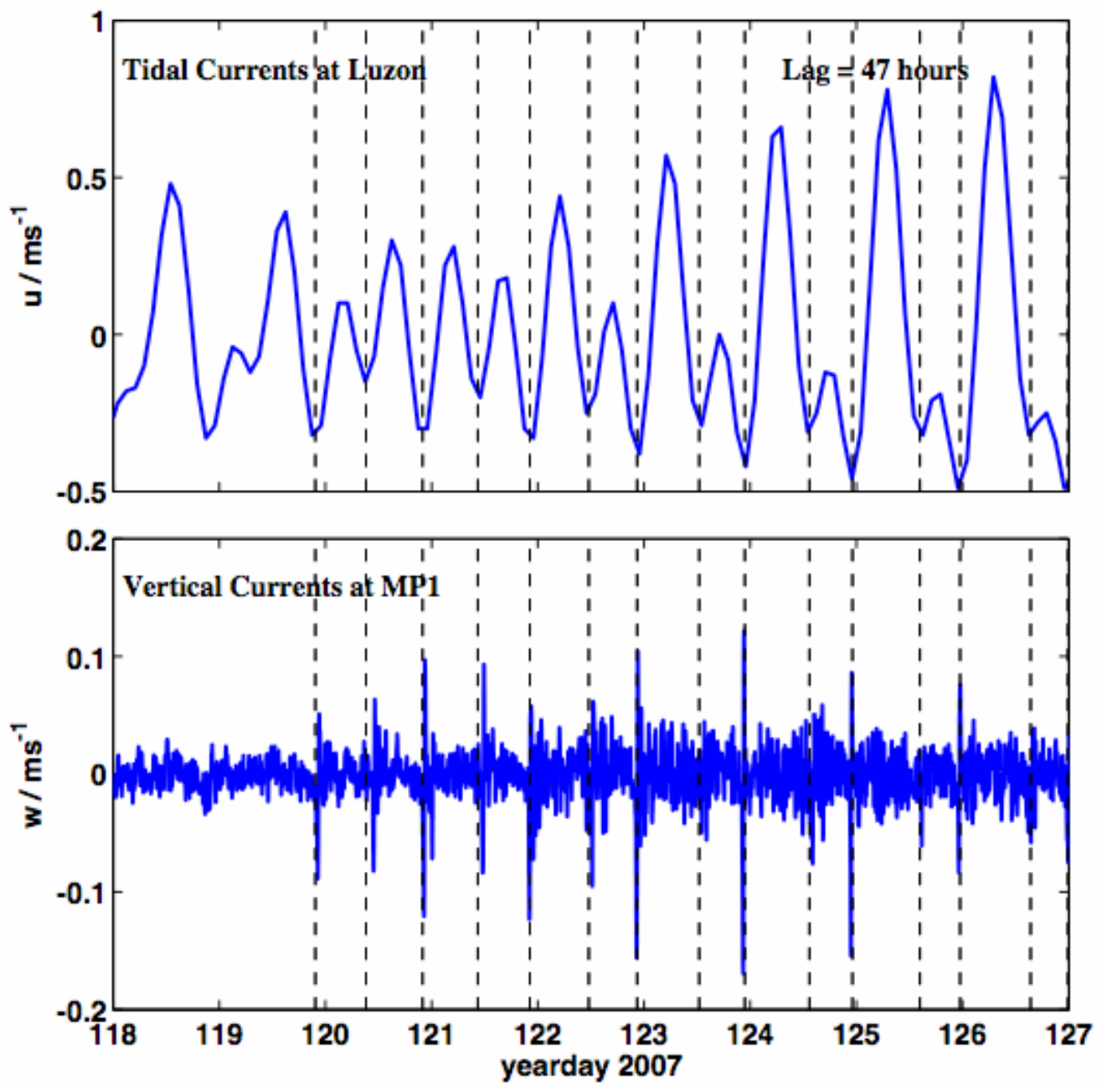

Figure 7: (top) Tidal currents at Luzon Strait. As in Figure 5, tidal currents are lagged by 47 hours. (bottom) Vertical velocity at $200 \mathrm{~m}$ measured at MP1.

Waves occur 47 hours after westward current maxima (dashed lines). 


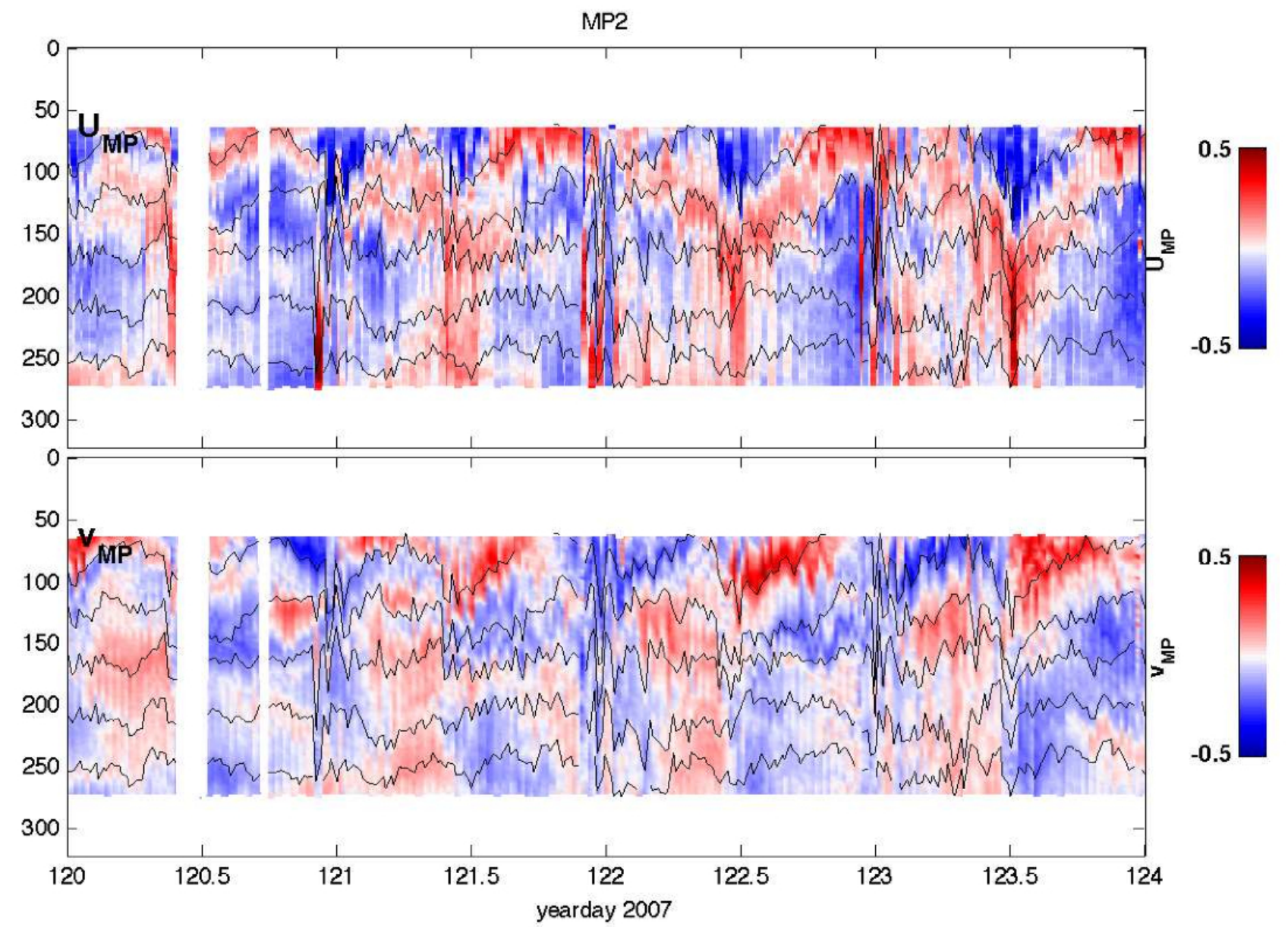

Figure 8: East-west (top) and north-south velocity (bottom) observed over a sample period at MP2, together with isopycnal depths (black).

\section{IMPACT/APPLICATIONS}

This rich dataset is only part of a large body of data collected during 2006 and 2007 by U.S. and Taiwanese investigators. It is clear that the data will support an increased understanding of the timing, energy budget, and dissipation mechanisms of both the internal tides and the nonlinear internal waves. Ongoing efforts, closely coordinated with the other PI's, will seek to unravel these issues.

\section{TRANSITIONS}

John Mickett, a former graduate student of Mike Gregg's, will begin part-time work on this project in the upcoming year as my postdoc.

\section{RELATED PROJECTS}

This work was closely coordinated with other PIs' efforts in this DRI; namely, microstructure work (St. Laurent), other ADCP's (Lien), conventional moorings (Tang, Ramp), as well as other shipboard field studies in 2007 (Pinkel/Klymak). Experiment design and planning was guided by modeling work and the ASIAEX and SCS05 experimental results. 
Ongoing NSF grants with Drs. Nash and Kunze to examine internal-tide reflection off the Oregon shelf, and with Drs. MacKinnon, Winters, Pinkel and Munk to examine long-range internal-tide propagation north of Hawaii, share many goals and techniques with this project.

\section{REFERENCES}

Alford, M., and R. Pinkel, Observations of overturning in the thermocline: The context of ocean mixing, J. Phys. Oceanogr., 30, 805-832, 2000.

Alford, M. H., Energy available for ocean mixing redistributed through long-range propagation of internal waves, Nature, 423, 159-163, 2003.

Alford, M. H., M. C. Gregg, and M. A. Merrifield, Structure, propagation and mixing of energetic baroclinic tides in Mamala Bay, Oahu, Hawaii, J. Phys. Oceanogr., 36, 9971018, 2006.

Dillon, T. M., Vertical overturns: A comparison of Thorpe and Ozmidov length scales, J. Geophys. Res., 87, 9601-9613, 1982.

Gregg, M., Scaling turbulent dissipation in the thermocline, J. Geophys. Res., 94, 96869698, 1989.

Kunze, E., L. Rosenfield, G. Carter, and M. C. Gregg, Internal waves in Monterey Submarine Canyon, J. Phys. Oceanogr., 32, 1890-1913, 2002.

Niwa, Y., and T. Hibiya, Three-dimensional numerical simulation of M2 internal tides generated around the continental shelf edge in the East China Sea, J. Geophys. Res., 109, doi:10.1029/2003JC001,923, 2004.

Ramp, S. R., D. Tang, T. F. Duda, J. F. Lynch, A. K. Liu, C. S. Chiu, F. Bahr, Y. R. Kim, and Y. J. Yang, Internal solitons in the northeastern South China Sea, part I: sources and deep water propagation, IEEE J. of Oceanic Engr., 2004.

Thorpe, S., Turbulence and mixing in a Scottish Loch, Philos. Trans. R. Soc. London Ser. A, 286, 125-181, 1977.

Zhao, Z., and M. H. Alford, Source and propagation of nonlinear internal waves in the northeastern South China Sea, J. Geophys. Res., 111, doi:10.1029/2006JC003,644, 2006.

Zhao, Z., V. Klemas, Q. Zheng, and X. Yan, Remote sensing evidence for baroclinic tide origin of internal solitary waves in the northeastern South China Sea, Geophys. Res.

Lett., 31, doi:10.1029/2003GL019,077, 2004.

\section{PUBLICATIONS}

No articles have been published this year on this project. 